
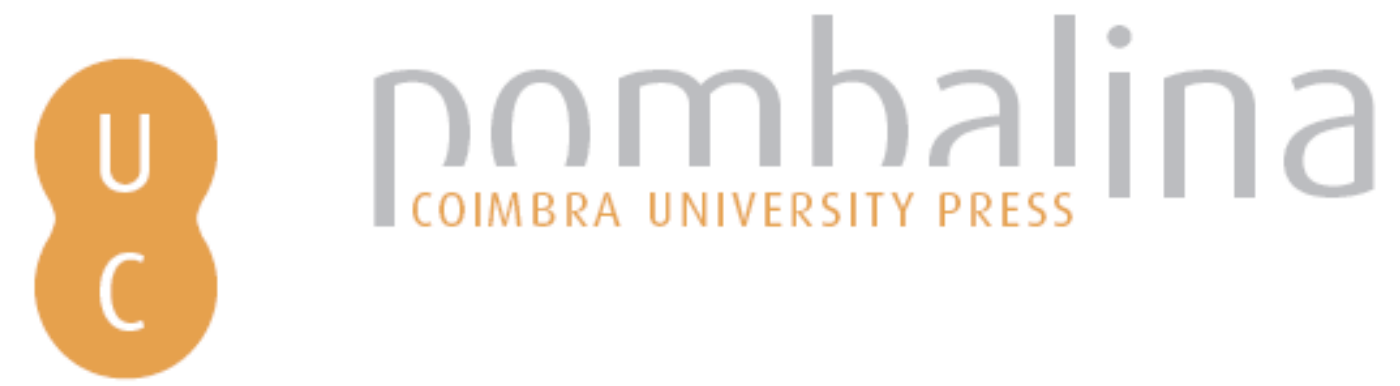

\title{
Uma tradição intemporal convertida em ideal alimentar ou o inverso?: acerca da "descoberta científica" da dieta mediterrânica
}

\author{
Autor(es): $\quad$ Silva, António \\ Publicado por: Imprensa da Universidade de Coimbra; Annablume \\ URL \\ persistente: URI:http://hdl.handle.net/10316.2/39610 \\ DOI: $\quad$ DOI:https://doi.org/10.14195/978-989-26-1191-4_1 \\ Accessed : $\quad$ 26-Apr-2023 15:55:37
}

A navegação consulta e descarregamento dos títulos inseridos nas Bibliotecas Digitais UC Digitalis, UC Pombalina e UC Impactum, pressupõem a aceitação plena e sem reservas dos Termos e Condições de Uso destas Bibliotecas Digitais, disponíveis em https://digitalis.uc.pt/pt-pt/termos.

Conforme exposto nos referidos Termos e Condições de Uso, o descarregamento de títulos de acesso restrito requer uma licença válida de autorização devendo o utilizador aceder ao(s) documento(s) a partir de um endereço de IP da instituição detentora da supramencionada licença.

Ao utilizador é apenas permitido o descarregamento para uso pessoal, pelo que o emprego do(s) título(s) descarregado(s) para outro fim, designadamente comercial, carece de autorização do respetivo autor ou editor da obra.

Na medida em que todas as obras da UC Digitalis se encontram protegidas pelo Código do Direito de Autor e Direitos Conexos e demais legislação aplicável, toda a cópia, parcial ou total, deste documento, nos casos em que é legalmente admitida, deverá conter ou fazer-se acompanhar por este aviso.

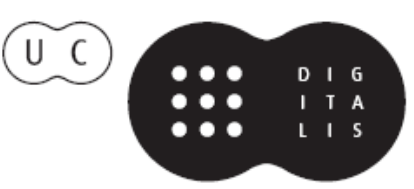




\title{
UMA TRADIÇÃO INTEMPORAL CONVERTIDA EM IDEAL ALIMENTAR OU O INVERSO? ACERCA DA "DESCOBERTA CIENTífica” DA DIETA MEDITERRÂNICA.
}

\section{A timeless tradition converted into a dietary ideal or the contrary? Beyond the scientific discovery of the Mediterranean Diet.}

\author{
António Silva \\ CEAACP \\ Universidade de Coimbra
}

Resumo: Esta comunicação tem como intuito abordar a questão da "descoberta científica" da dieta mediterrânica, recentemente elevada a património cultural imaterial da Humanidade, numa perspectiva histórica e genealógica. Para tal, é preciso primeiro dar conta dos contextos históricos e sociais que lhe serviram de inspiração - as zonas rurais da ilha de Creta e os bairros populares de Nápoles - mas também daquele da comunidade científica e da classe média americana do pós-guerra. Este regresso às origens tem por objectivo demonstrar que a dieta mediterrânica não é propriamente uma tradição milenar, expressão de uma "sabedoria popular" perpetuada inalterada até ao momento da sua descoberta científica, mas sim o fruto de uma disciplina alimentar imposta pela necessidade, no primeiro caso e, no segundo caso, de uma nostalgia alimentar, reinterpretadas à luz de um ideal vegetariano tendencialmente puritano, que tem a sua origem um século antes nos Estados Unidos da América.

Palavras-chave: dieta mediterrânica, descoberta científica, nutrição, movimentos reformistas, Estados Unidos da América, Nápoles, Creta.

Aвsтract: This article is about the "scientific discovery" of the Mediterranean diet, recently promoted by UNESCO as a intangible cultural heritage of humanity, analysed here from an historical and genealogical perspective. To do so, it is necessary first to take into account the historical and social contexts underlying its discovery - the rural areas of Crete and the popular districts of Naples - as well as those of the scientific community and of the post-war American middle class. This return to the past is intended to demonstrate that the Mediterranean diet is not really a timeless tradition, an expression of "popular wisdom" perpetuated and unchanged until the time of its scientific discovery, but rather the result of a dietary discipline imposed in the first case by need and, in the second case, by food nostalgia, reinterpreted in the light of a Puritan vegetarian ideal, which has its origins a century ago in the United States of America.

KEYWORDs: Mediterranean diet, scientific discovery, nutrition, reform movements, United States of America, Naples, Crete. 


\section{UMA HISTÓRIA MAL CONTADA ${ }^{1}$}

Os nutricionistas encorajam-nos regularmente a adoptar uma dieta saudável: rica em frutas, vegetais e cereais. Aconselham-nos ao mesmo tempo a moderar o consumo de alimentos ricos em gordura e proteína animal de que tanto gostamos. Esta reforma dos nossos hábitos alimentares é-nos apresentada como uma espécie de retorno ao modelo alimentar dos primórdios da civilização ocidental que, até há bem pouco tempo atrás, teria sido perpetuado inalterado pelos habitantes mais pobres das zonas menos desenvolvidas do Mediterrâneo. Essa crença é fundamentada em estudos epidemiológicos realizados após o fim da Segunda Guerra Mundial na ilha de Creta e na cidade de Nápoles, estudos esses que forneceram evidências científicas de que a incidência de acidentes cardiovasculares era então muito menor no sul da Itália e na Grécia do que nos países industrializados do norte onde o consumo de carne era maior. Os organismos oficiais de saúde apresentam-nos, desde então, a dieta mediterrânica como um modelo alimentar que devemos seguir se quisermos ter uma vida longa e saudável ${ }^{2}$.

Esta comunicação tem como intuito abordar a questão da "descoberta científica” da dieta mediterrânica, recentemente elevada a património cultural imaterial da humanidade, numa perspectiva histórica e genealógica. Para tal, é preciso primeiro dar conta dos contextos históricos e sociais que lhe serviram de inspiração - as zonas rurais da ilha de Creta e os bairros populares de Nápoles mas também daquele da comunidade científica e da classe média americana do pós-guerra. Este regresso às origens tem por objectivo demonstrar que a dieta mediterrânica não é propriamente uma tradição intemporal, expressão de uma "sabedoria popular" 3 perpetuada inalterada até ao momento da sua descoberta pelos cientistas, mas sim o fruto de uma disciplina alimentar imposta pela necessidade, no primeiro caso e, no segundo caso, de uma nostalgia alimentar, reinterpretadas à luz de um ideal vegetariano tendencialmente puritano, que tem a sua origem um século antes nos Estados Unidos da América.

\section{História(s) da descoberta Científica de UMA TRAdição...}

1948 é hoje muitas vezes apontado como o ano da descoberta científica da dieta mediterrânica ${ }^{4}$. O governo grego tinha convidado a Fundação

${ }^{1}$ Este artigo retoma algumas das ideias desenvolvidas no segundo volume de uma trilogia sobre os discursos e as práticas alimentares no Mediterrâneo, intitulado "La diète méditerranéenne", que foi recentemente publicado pela editora L'Harmattan na colecção "Questions alimentaires et gastronomiques" (Silva 2015).

${ }^{2}$ Poulain 2006: 8-9.

${ }^{3}$ Palma et alii 2012: 155 .

${ }^{4}$ Nestle 1995: 1314 S. 
Rockefeller a coordenar um programa de pesquisa que visava definir as bases para uma política de melhoria da qualidade de vida dos Gregos ${ }^{5}$ na expectativa de impedir, a longo prazo, que os habitantes deste país fossem seduzidos pelos ideais comunistas ${ }^{6}$. A ideia era portanto, à partida, estudar diferentes aspectos do quotidiano dos habitantes de Creta, inclusive os seus hábitos alimentares. A Fundação confia a um epidemiologista americano, Leland G. Allbaught, a responsabilidade de coordenar uma equipa de amas voluntárias da Cruz Vermelha, que irá levar a cabo um inquérito junto de uma amostra significativa de famílias da ilha7.

Este estudo, cujos resultados são publicados em 1953, apresenta pela primeira vez um retrato detalhado e rigoroso dos hábitos alimentares dos Cretenses logo após o fim da guerra. Allbaught conclui que a dieta dos habitantes da ilha era muito mais frugal do que a dos Americanos nessa mesma época. $\mathrm{O}$ consumo de alimentos de origem vegetal era então muito significativo nessa ilha quando comparado com outras regiões da Grécia e muito mais ainda quando comparado com os Estados Unidos. Este investigador observou ainda que a taxa de mortalidade era particularmente baixa antes e depois da guerra ${ }^{8}$. Defende também neste estudo que a dieta dos Cretenses manteve-se inalterada durante quarenta séculos, sempre à base de azeitonas, cereais, leguminosas, plantas silvestres, ervas aromáticas, grandes porções de pão, combinados em preparados ensopados em azeite e uma porção reduzida de carne de cabra, de leite, de peixe e de vinho9. A ideia de que uma tradição alimentar intemporal tinha sido preservada intacta nalgumas regiões mais atrasadas do Mediterrâneo acabava de se tornar uma verdade científica, ainda hoje consensualmente aceite por muitos investigadores na área das Ciências da Saúde ${ }^{10}$.

Convém no entanto salientar que é apenas enquanto exemplo de região subdesenvolvida que Allbaught se interessa por Creta e não ainda como amostra representativa das outras regiões do Mediterrâneo. O conceito de "dieta mediterrânica", tal como o usamos hoje, irá nascer muito mais tarde, num laboratório da Universidade de Minnesota, tendo por autor um outro epidemiologista americano que ficou para a posteridade como sendo o pai da descoberta científica desta dieta: Ancel Keys ${ }^{11}$. Este investigador começa a

\footnotetext{
${ }^{5}$ Rockefeller 1948: 98.

${ }^{6}$ Farley 2004: 278.

${ }^{7}$ Allbaught 1953: 3 .

${ }^{8}$ Allbaught 1953: 135.

${ }^{9}$ Allbaught 1953: 100.

${ }^{10}$ A discussão em volta da noção de dieta tradicional entre cientistas e antropólogos envolvidos na preparação da candidatura da dieta mediterrânica a património da Humanidade é a prova de que essa crença está ainda bem enraizada nesse meio (Turmo et alii 2012).

${ }_{11}$ Reguant-Alleix 2012: 46.
} 
interessar-se pela relação entre o regime alimentar e as doenças cardiovasculares logo após o fim da Segunda Guerra Mundial. Toma então conhecimento de que o número de acidentes cardiovasculares tendeu a diminuir na Holanda a seguir ao conflito ${ }^{12}$, apesar de os efeitos da subnutrição se terem feito sentir mais neste país do que em qualquer outra parte da Europa ${ }^{13}$. Nos Estados Unidos, os incidentes coronários já eram uma das principais causas de mortalidade pelo menos desde 1921. Uma simples consulta dos obituários publicados nos jornais de Minneapolis leva Keys a concluir que esse tipo de doença parecia afectar a classe dos "homens de negócios" mais do que qualquer outra. Em 1946, já este investigador tinha começado a monitorizar o estado de saúde de 286 empresários locais, que assumiram o compromisso de se sujeitarem a exames periódicos até o final das suas vidas ${ }^{14}$. Este estudo, conhecido como Minnesota study servirá frequentemente de referência para o estado de saúde dos "colarinhos brancos" das áreas urbanas dos Estados Unidos nos trabalhos posteriores de Keys ${ }^{15}$. O epidemiologista tinha também conhecimento de experiências com animais, levadas a cabo na década de 1930, demonstrando que a dieta alimentar tinha uma influência sobre os níveis de colesterol no sangue ${ }^{16}$ e sobre o risco de morte devido a um acidente cardiovascular ${ }^{17}$. Com base nisso, Keys formulou a hipótese que iria mudar radicalmente o rumo de sua carreira: a dieta alimentar dos Americanos mais abastados, rica em gordura animal e em carne, aumentava significativamente o risco de sofrerem um acidente cardiovascular.

O interesse de Ancel Keys pela dieta dos Napolitanos surge alguns anos mais tarde, quando preside a primeira conferência organizada conjuntamente pela Food and Agriculture Organization e pela World Health Organization, em Roma em 1951, onde se discutem os efeitos da subnutrição sobre a saúde. Questionado sobre a relação entre dieta alimentar e doenças coronárias, Gino Pergami, professor de Fisiologia na Universidade de Nápoles, revela a Keys que os óbitos devidos a esta causa eram muito raros no sul da Itália. O investigador americano, intrigado, decide visitar a Riviera Vesuviana com sua esposa, Margareth, para descobrir, por si mesmo, a razão de tão baixa frequência de doenças cardiovasculares. $\mathrm{O}$ casal observa que os Napolitanos mais abastados, que comem carne todos os dias, à semelhança dos "colarinhos brancos" americanos, são os únicos a sofrerem de ataques cardíacos. Os homens de negócios locais tendem também a terem níveis elevados de

\footnotetext{
12 Tucker 2007: 201.

${ }^{13}$ Voglis 2006: 22-23.

${ }^{14}$ Tucker 2007: 202.

${ }^{15}$ Keys 1953a: 130.

${ }^{16}$ Só mais tarde se veio a distinguir o bom (HDL) e o mau (LDL) colesterol.

${ }_{17}$ Keys 1980: 14.
} 
colesterol, ao contrário dos outros moradores da cidade. Constata igualmente que, ao contrário da elite, o resto da população de Nápoles consome pouca carne. Keys decide em seguida organizar um estudo piloto juntamente com os seus colegas italianos com base numa amostra composta por membros do corpo de bombeiros e das milícias urbanas oriundos da classe operária, com o intuito de confirmar as suas suspeitas ${ }^{18}$.

Após estes primeiros estudos epidemiológicos em Nápoles, Keys vai conceber um programa internacional de investigação que incide sobre a relação entre a dieta e as doenças cardiovasculares, para testar o que é ainda, naquela época, uma simples hipótese de trabalho ${ }^{19}$. O cientista vai convencer colegas finlandeses e japoneses a reproduzir o seu protocolo de análise nos seus países de origem, de modo a poder comparar os dados epidemiológicos recolhidos nos Estados Unidos com outros países onde a dieta alimentar é tradicionalmente muito rica, no primeiro caso, e muito pobre, no segundo caso, em carne e gordura animal ${ }^{20}$. Os investigadores envolvidos neste projecto pretendiam agora comparar os dados epidemiológicos relativos a países desenvolvidos com aqueles de países subdesenvolvidos do Sul da Europa, cujos habitantes teriam supostamente permanecido fiéis à sua dieta tradicional ${ }^{21}$. Em 1956, cientistas da Grécia, da Itália, da Jugoslávia e da Holanda já fazem parte desse projecto de investigação internacional ${ }^{22}$, que posteriormente levaria a comunidade científica a acreditar que a teoria de Keys estava correcta.

Os coordenadores da equipa grega, Cristo Aravanis e Andy Dontas, optam por Corfu, onde a dieta alimentar já era muito semelhante àquela observada nos outros países da Europa. Creta também é escolhida por duas razões: quando os cientistas iniciaram a sua investigação nessa ilha, o azeite continuava a ser a fonte de gordura privilegiada da alimentação dos seus habitantes e, para além disso, os acidentes coronários ainda eram muito raros nesta ilha ${ }^{23}$. Em 1958, a equipa abre uma nova frente de trabalho na Jugoslávia. A missão de estudo na Itália começa três anos mais tarde, dando agora preferência às zonas rurais tanto no norte, onde a dieta é mais rica em gordura animal, como no sul do país, onde a dieta era mais pobre em carne. A equipa esperava que as tradições alimentares se mantivessem ainda bem preservadas nessas zonas à margem do desenvolvimento industrial ${ }^{24}$.

\footnotetext{
${ }^{18}$ Keys et alii 1954.

${ }^{19}$ Keys 1980: 1.

${ }^{20}$ Tucker 2007: 203.

${ }^{21}$ Blackburn 1999.

${ }^{22}$ Tucker 2007: 203.

${ }^{23}$ Blackburn 1999.

${ }^{24}$ Blackburn 1999.
} 
Keys e a sua equipa contavam agora com a participação de 12,763 pessoas de sete países diferentes, o que os leva a baptizarem o estudo: Seven Countries Study ${ }^{25}$. Este projecto de pesquisa, que se prolongou durante 12 anos, confirmou a taxa excepcionalmente baixa de mortalidade causada por acidentes coronários nos países do Mediterrâneo e, especialmente, em Creta ${ }^{26}$. O epidemiologista concluiu assim que o elevado número de vítimas de acidentes cardiovasculares observado nos Estados Unidos estava directamente relacionado com um teor de colesterol excessivamente elevado, resultando de uma dieta demasiadamente rica em carne e em gordura animal. Poe essa razão, recomendará mais tarde aos seus compatriotas que adoptem a dieta tradicional dos Napolitanos e dos Cretenses, mais frugal e tendencialmente vegetariana ${ }^{27}$.

\section{... QUE NUNCA FOI BEM O QUE ERA SUPOSTO SER ...}

Em abono da verdade, os Cretenses que participaram no estudo Rockefeller não partilhavam de todo o entusiasmo dos cientistas pela sua dieta. Quando Allbaught leva a cabo o seu inquérito, a população de Creta acaba de sair da Segunda Guerra Mundial e, tal como aquela que vivia nas outras regiões da Grécia, passa fome ${ }^{28}$. A guerra civil que durou até 1949, retardou a recuperação económica do país ${ }^{29}$. No entanto, se acreditarmos no que relata Allbaught a esse respeito ${ }^{30}$, a maioria das famílias que participaram no estudo Rockefeller seguia uma dieta alimentar adequada, fazendo um bom proveito dos recursos naturais da ilha. O estudo revela ainda um pormenor importante: os habitantes da ilha não eram frugais por natureza, mas sim por necessidade. Cinco famílias sobre seis não se sentiam nada satisfeitas com o que comiam diariamente. Uma família queixava-se mesmo: "Estamos com fome a maior parte do tempo!" ${ }^{11}$. Os Cretenses não eram fiéis a uma dieta quase vegetariana à base de alimentos endógenos porque gostavam, mas por não terem os recursos económicos para adquirir alimentos que aspiravam poder comer todos os dias: carne, arroz, peixe, pasta, manteiga e queijo, seguindo a ordem de preferência destes. $72 \%$ dos entrevistados também declarou às amas da Cruz Vermelha que a carne era a sua comida favorita. Os Cretenses do pós-guerra sonhavam, em suma, poder comer o mesmo que os habitantes dos países desenvolvidos, ou seja, ter uma dieta muito mais rica em proteína

\footnotetext{
${ }^{25}$ Keys 1980: 15.

${ }^{26}$ Dernini et alii 2012: 78.

${ }^{27}$ Keys 2006: 30.

${ }^{28}$ Laiou-Thomadakis 1980: 35.

${ }^{29}$ Koliopoulos et alii 2002: 127.

${ }^{30}$ Allbaught 1953: 31.

${ }^{31}$ Allbaught 1953: 105.
} 
e gordura animal. Allbaught aconselha-os de resto a fazer isso mesmo: comer mais alimentos ricos em proteína animal (carne, peixe, queijo e ovos), de acordo com as recomendações nutricionais do United States Department of Agriculture (USDA), em vigor nos Estados Unidos nessa mesma altura.

Ao contrário dos Cretenses, os Napolitanos do pós-guerra valorizavam a sua dieta alimentar. Os anos que se seguiram à libertação de Nápoles foram muito difíceis. Uma investigação realizada em 1951, a pedido do Parlamento italiano, levou os seus autores a concluir que as condições de vida no sul da Itália eram muito idênticas às observadas nessa mesma região no quadro de um estudo semelhante realizado em 1877. Tal como os seus avós, muitos trabalhadores não consumiam vinho ou carne, excepto por vezes nos feriados ${ }^{32}$. Porém, no decorrer do estudo Seven Countries, a Itália entra numa nova fase de crescimento económico, que leva a um aumento muito substancial do poder de compra das famílias da classe trabalhadora em todo o país. Os Italianos vão, no entanto, manter-se fiéis por um tempo aos produtos que lhes eram familiares antes da guerra. Numa época de profundas mudanças ao nível económico e social, a incorporação de alimentos torna-se uma fonte latente de ansiedade. Consumir preparações culinárias familiares, à base de cereais, legumes e citrinos, tem a virtude de acalmar o consumidor italiano. Embora a dieta alimentar seja agora mais rica em proteína animal, a carne tem de ser preparada em conformidade com as recomendações dos livros de culinária do século XIX ou do tempo do fascismo. A indústria agro-alimentar nacional soube ir ao encontro da nostalgia gustativa dos consumidores, apostando no aumento da produção de alimentos considerados tradicionais pelo público em geral, como a pasta, as azeitonas, o tomate, o vinho e o pão, em vez de investir em novos produtos oriundos da América como a Coca Cola ou as bolachas Ritz, que os Italianos descobrem nessa mesma época mas com um entusiasmo muito relativo ${ }^{33}$. A dieta dos Napolitanos, ao longo das décadas de 1950 e 1960, já não era propriamente uma dieta de subsistência, como a dos Cretenses alguns anos antes. Ao contrário deles, os Napolitanos valorizavam os alimentos que comiam todos os dias, sendo vistos como uma conquista social do popolo minuto, que tinha agora um acesso diário a alimentos como a pasta e o vinho, reservado no passado aos eventos festivos.

Os dois estudos epidemiológicos que são hoje incansavelmente invocados como referência da dieta mediterrânica ${ }^{34}$, reportam-se portanto a duas realidades sociais e culturais bem datadas, muito específicas e sobretudo bem diferenciadas. Mas para Ancel Keys, e muitos cientistas depois dele,

\footnotetext{
${ }^{32}$ Helstosky 2004: 133.

${ }^{33}$ Helstosky 2004: 127.

${ }^{34}$ Apenas a título de exemplo: Nestle 1995. Willett et alii 1995.
} 
não havia dúvida de que esses dois estudos retratavam uma mesma dieta, vegetariana, moderada e benéfica para a saúde e, embora Keys tenha acabado por reconhecer-lhe uma certa variabilidade espacial e temporal, prevaleceu desde então a ideia de que a dieta tradicional dos habitantes pobres dessa região do mundo era totalmente distinta daquela dos habitantes do novo continente ${ }^{35}$.

\section{... INSPIRADA NUM IDEAL PURITANO ...}

Se pensarmos bem, o facto de a dieta mediterrânica ter sido promovida primeiro nos Estados Unidos como modelo alimentar é, à primeira vista, um pouco paradoxal. Como é sabido, os Americanos eram desde há muito conhecidos por serem grandes consumidores de carne e a sua dieta foi desde sempre pobre em frutas e hortaliças ${ }^{36}$. Mas sendo o primeiro país do mundo a entrar na era do que hoje chamamos a modernidade alimentar ${ }^{37}$, é também lá que a rejeição desse novo padrão, caracterizado por um elevado consumo de carne, ganha pela primeira vez uma projecção social expressiva. Antes de se tornar uma questão de Estado, a reforma dos hábitos alimentares foi primeiro objecto de um activismo individual inspirado por um ideal de vida tendencialmente puritano. Os precursores do movimento viam o vegetarianismo antes de mais como uma forma de retorno a um modo de existência mais natural. Tal como os cientistas do pós-guerra, os primeiros reformadores valorizavam o modo de vida das sociedades agrárias tradicionais, em contraponto com a civilização industrial, responsável pela degeneração, tanto física como moral da sociedade moderna ${ }^{38}$. Desde a década de 1830 , pregadores como o Reverendo William S. Graham lançam apelos em prol do retorno à dieta vegetariana ${ }^{39}$, que Deus tinha imposto a Adão e Eva desde o momento da sua criação ${ }^{40}$. Inspirado pelas teorias vitalistas e atento aos primeiros avanços da fisiologia na Europa ${ }^{41}$, Graham defendia que o corpo humano era animado por uma força vital que a actividade sexual, o consumo de álcool, de carne e de especiarias tendiam a diminuir ${ }^{42}$. A adopção de uma dieta vegetariana, preconizada inicialmente por razões espirituais, era, assim, convenientemente validada pelas últimas descobertas científicas. O ideal puritano que inspirava este movimento precursor do vegetarianismo moderno

\footnotetext{
${ }^{35}$ Keys 1995. Keys 2006: 60 .

${ }^{36}$ Levenstein 2003: 4.

${ }^{37}$ Poulain 2002: 29-34.

${ }^{38}$ Meyer-Renschhausen et alii 1999: 329.

${ }^{39}$ Levenstein 1997: 845.

${ }^{40}$ Silva 2013: 13-17.

${ }^{41}$ Lavabre-Bertrand 2013: 5-6.

${ }^{42}$ Graham 1849.
} 
conquistou um público muito ecléctico, oriundo de seitas milenaristas, como os Adventistas do Sétimo Dia, do movimento intelectual transcendentalista e de comunidades utópicas socialistas que sonhavam isolarem-se longe da decadência da civilização ocidental ${ }^{43}$.

A cruzada puritana contra o consumo de alimentos estimulantes vai progressivamente levar a que a nutrição acabe mesmo por tornar-se uma área de intervenção privilegiada do Governo federal ${ }^{44}$. Será, no entanto, preciso esperar a criação do USDA, em 1862, para que se constitua uma classe de profissionais com formação especializada, capaz de dar início a um movimento de reforma dos hábitos alimentares sustentado em conhecimentos verdadeiramente científicos ${ }^{45}$. De hora em diante, o USDA dará aos investigadores a oportunidade de apresentarem os resultados das suas experiências sob a forma de recomendações e de relatórios destinados, num primeiro tempo, apenas a orientar as políticas agrícolas do Governo. As primeiras estações experimentais agronómicas, que começam a laborar nessa mesma época, vão por sua vez proporcionar um quadro institucional, financeiro e logístico aos cientistas que pretendiam levar a cabo projectos de investigação com o intuito de aumentar a produção agrária e, mais tarde, melhorar a dieta dos Americanos, em estreita colaboração com o USDA ${ }^{46}$. As medições calorimétricas efectuadas pelos cientistas nestas estações vão rapidamente dar lugar a recomendações com o objectivo de racionalizar os hábitos alimentares dos consumidores, dando-lhes a conhecer as quantidades apropriadas de diferentes tipos de nutrientes que eles necessitavam de ingerir regularmente ${ }^{47}$. Foi através desta mesma nomenclatura quantitativa que os Americanos se tornaram cada vez mais cientes da especificidade do seu padrão alimentar ${ }^{48}$. Uma vez reduzido a uma sequência de valores numéricos, era agora possível comparar os hábitos alimentares de grandes conjuntos de indivíduos agrupados em função de critérios objectivos, obliterando por completo as trajectórias de vida pessoais, as crenças e as tradições alimentares próprias de cada comunidade.

A partir do final do século XIX, causas sociais sobrepõem-se já às preocupações religiosas e morais que motivaram os primeiros reformadores. A dieta vegetariana, que era anteriormente entendida principalmente como uma forma de fisiologia moral, tornou-se nessa altura o instrumento de um outro movimento de reforma unido em volta de uma concepção menos liberal da economia, em reacção à boa consciência burguesa dominante nas elites

\footnotetext{
${ }^{43}$ Levenstein 1997: 846.

${ }^{44}$ Rosenberg 1997: 109.

${ }^{45}$ Nestle 2007: 33.

${ }^{46}$ Mudry 2009: 25.

${ }^{47}$ Atwater 1895: 368.

${ }^{48}$ Atwater 1902: 36.
} 
até então. Os seus membros acreditavam na necessidade de uma distribuição mais justa dos recursos extensíveis a toda a sociedade em consonância com as aspirações das primeiras organizações laborais da classe operária que ganham força neste mesmo período ${ }^{49}$. A retórica quantitativa desenvolvida ao longo das décadas anteriores pelos investigadores das estações experimentais é bem acolhida por essa nova geração de reformadores que tem, agora, como objectivo melhorar as condições de vida dos operários, para evitar que estes sejam tentados a aderir aos movimentos radicais ${ }^{50}$. A ideia era incentivar os membros dessa classe a consumir menos carne, menos álcool e também menos frutas e legumes que, antes da descoberta das vitaminas, eram vistos pelos cientistas apenas como uma forma dispendiosa de hidratar o corpo. Os trabalhadores poderiam deste modo usar o excedente de rendimento assim libertado para melhorar as condições de vida nos seus lares, a sua indumentária e adquirir outros bens de consumo, aproximando-se pela mesma ocasião do padrão de vida característico da classe média. Mas, como o percebeu muito bem $\mathrm{H}$. Levenstein ${ }^{51}$, os operários não emigraram para a América para comer feijões cozidos, mas sim para comer carne de vaca. E, por isso mesmo, a maioria dos membros da classe trabalhadora não mordeu o isco. Os imigrantes italianos insistiam, por seu lado, em continuar a comer legumes e frutas frescas, contrariando as recomendações dos reformadores ${ }^{52}$. Após este fracasso, os movimentos vegetarianos vão cada vez mais dirigir os seus apelos à classe média e à alta sociedade americana ${ }^{53}$, sendo certo que os mais abastados eram de qualquer modo os únicos nessa época a sofrerem de problemas de saúde causados pelo excesso de comida, ao contrário do resto da população que morria devido a doenças derivadas de carências alimentares ${ }^{54}$.

Esta primeira incursão pelo social marca o início do processo gradual de secularização dos movimentos de reforma alimentar. O legado de Graham não seria, porém, imediatamente esquecido. Uma nova geração de pregadores carismáticos, como o "Doutor” John Harvey Kellogg, era ainda muito popular durante a "Belle Époque". A nata da sociedade da década de 1900 frequentava o "sanitarium" vegetariano que Kellogg concebeu nas antigas instalações dos Adventistas do Sétimo Dia em Battle Creek. A dieta que preconizava aos seus "pacientes" era totalmente inspirada nos preceitos de Graham: a comida tinha de ser preparada de uma forma simples, ou seja o mais próximo possível do estado em que Deus a criou, privilegiando o consumo de cereais em

\footnotetext{
${ }^{49}$ Meyer-Renschhausen et alii 1999: 325.

${ }^{50}$ Bevilacqua 2010: 6.

${ }^{51}$ Levenstein 1997: 847.

${ }^{52}$ Haber 1997: 1055S.

${ }^{53}$ Levenstein 1997: 848.

${ }^{54}$ Meyer-Renschhausen et alii 1999: 324.
} 
detrimento da carne. Tendo olho para o negócio, John Kellogg encarrega o seu irmão, Will Keith, de lançar no mercado a sua própria marca de flocos de milho prontos para comer em $1895^{55}$. Os flocos de cereais irão rapidamente substituir o pequeno almoço de tradição britânica à base de salsicha, ovos e cerveja que muitas famílias da classe média comiam até então ${ }^{56}$. O facto de este ser hoje o pequeno almoço predilecto de muitos lares em todo o mundo não deixa dúvidas quanto ao facto de a influência desses reformadores sobre os padrões alimentares dos consumidores ser muito mais duradoira do que as crenças religiosas que a motivaram. O próprio Kellogg, grande admirador da investigação de Louis Pasteur sobre os micróbios, colocará cada vez maior ênfase na higiene pessoal em detrimento da pureza moral, dando gradualmente lugar a uma espécie de culto secular centrado no corpo, incompatível com as crenças religiosas dos seus companheiros adventistas, vindo mesmo a ser expulso pelos outros membros da congregação em $1903^{57}$.

A classe média aderiu, uma vez mais, com entusiasmo ao apelo destes reformadores, ao contrário da classe trabalhadora, hostil a esse ideal de vida puritano, como foi atrás referido. Mas para aqueles que tinham poder de compra e alguma instrução, a adopção de uma dieta vegetariana, à base de alimentos minimamente processados, tornou-se um meio eficaz de aliviar a ansiedade crescente da incorporação de alimentos pouco saudáveis, que se intensificou à medida que o processo então em curso, de segmentação da cadeia alimentar, se generalizava. Em 1869, a rede ferroviária dos Estados Unidos já se estendia desde o Atlântico ao Pacífico, ligando regiões distantes que começavam a especializarem-se em diferentes segmentos da produção alimentar ${ }^{58}$. A intensificação do processo de relocalização do consumo alimentar e, nomeadamente de carne, teve por consequência um desaparecimento gradual dos elementos interpessoais de confiança capazes de tranquilizar os consumidores sobre a origem dos alimentos que ingeriam ${ }^{59}$. Foi somente em 1904, após a publicação do romance de Upton Sinclair intitulado The Jungle, que denunciava as deploráveis condições sanitárias e a exploração dos trabalhadores imigrantes nos matadouros de Chicago, que a opinião pública tomou consciência do lado negro do império da indústria da carne criado de raiz ao longo das décadas anteriores pelas grandes empresas e que eles desconheciam por completo até então. Após o escândalo de Chicago, o poder político será forçado a manter um controle mais activo sobre a qualidade e a frescura da carne. No entanto, nessa mesma época, nenhum cientista

\footnotetext{
${ }^{55}$ Levenstein 2003: 33.

${ }^{56}$ Ferrières 2002: 425.

${ }^{57}$ Meyer-Renschhausen et alii 1999: 332.

${ }^{58}$ Levenstein 2003: 30.

${ }^{59}$ Ferrières 2002: 418.
} 
ponderava ainda a hipótese de restringir o consumo de qualquer categoria de alimentos, independentemente de chegarem ou não em boas condições à mesa do consumidor. Na década de 1920, o USDA já recomenda o consumo de legumes e frutas, mas só por serem ricos em minerais e vitaminas, recentemente descobertos pelos cientistas das estações experimentais ${ }^{60}$. Mas nessa mesma época, esta instituição ainda estava bem longe de aconselhar os Americanos a reduzirem o consumo de determinadas categorias de alimentos considerados prejudiciais para a saúde quando consumidos em excesso. Será preciso esperar pelo estudo "Seven Countries", para serem criadas as condições necessárias para que haja uma mudança de paradigma nutricional neste país.

\section{... CONVERTIDO EM TRADIÇÃO MILENAR ...}

Durante a Segunda Guerra Mundial, o consumo de carne continuava a ser maior nos Estados Unidos do que em qualquer outro país do mundo ${ }^{61}$. De regresso a casa, os veteranos do "exército melhor nutrido do mundo" estavam acostumados a consumir porções generosas de alimentos e nomeadamente carne em doses abundantes ${ }^{62}$. Da base ao topo da pirâmide social, os Americanos cultivavam agora um estilo de vida desinibido. Completamente rendidos à conveniência, não sentiam qualquer tipo de culpa por comer em excesso. É neste contexto que a cruzada contra a carne inaugurada um século antes pelo reverendo Graham vai, uma vez mais, contra qualquer expectativa, ganhar um novo fôlego sob a forma do movimento a que H. Levenstein ${ }^{63}$ chama de "Negative Nutrition". Ancel Keys é precisamente um dos precursores do renascer do movimento reformador no pós-guerra. Na sequência dos trabalhos pioneiros deste epidemiologista e da sua equipa sobre a relação entre a dieta alimentar, o risco coronário e o teor de colesterol no sangue, os cientistas são agora cada vez mais numerosos a considerar que o consumo excessivo de carne é nocivo para a saúde ${ }^{64}$. Porém, os benefícios físicos de uma dieta moderada, pobre em carne e em gordura animal, sobrepõem-se agora totalmente aos benefícios espirituais desta dieta, enaltecidos pelos primeiros reformadores.

Contrariamente aos seus antecessores, que consideravam uma dieta sem carne como uma fonte de pureza espiritual e moral, Keys e a sua equipa reviam apenas neste regime alimentar tendencialmente vegetariano a promessa de uma vida longa e saudável. É paradoxalmente a mesma retórica baseada na linguagem quantitativa, usada anteriormente nos guias nutricionais do USDA

\footnotetext{
${ }^{60}$ Stiebeling et alii 1933: 10 .

${ }^{61}$ Levenstein 1997: 853.

${ }^{62}$ Levenstein 1993: 89.

${ }^{63}$ Levenstein 1997: 856.

${ }^{64}$ Nestle 2007: 39.
} 
para recomendar o consumo de proteína animal, que será, a partir de então, mobilizada pelos cientistas para convencer a opinião pública de que uma dieta rica em gordura animal e em carne era prejudicial. Como não podia deixar de ser, Keys usou esse mesmo tipo de argumentos para convencer os seus colegas das benesses de uma dieta pobre em carne. Sintetizou os dados que comprovavam a sua teoria num gráfico que representava a relação entre a percentagem de calorias ingeridas sob a forma de gordura e o número de mortes devido a acidentes coronários em vários países. Os pontos que representavam a convergência entre essas duas variáveis para cada país podiam ser unidos sob a forma de uma curva semi-logarítmica quase perfeita tendo, na base, o Japão e a Itália e, no topo, os Estados Unidos, seguidos imediatamente pelas nações do mundo anglo-saxónico, como o Canadá, a Austrália, a Inglaterra e o País de Gales ${ }^{65}$. Não seria porém sob essa forma que a descoberta seria dada a conhecer ao grande público. Ancel Keys estava plenamente consciente de que a retórica quantitativa desenvolvida pelos investigadores das estações experimentais não era a mais adequada para divulgar as suas ideias fora da comunidade científica. O livro que ele publica em 1959, em colaboração com sua esposa, intitulado Eat well and stay well, marca uma verdadeira ruptura com a estratégia de comunicação que orientou as campanhas nutricionais do USDA no passado.

Em vez de tentar vender o seu modelo dietético ideal ao grande público como um novo regime alimentar, Keys convidou os seus compatriotas a adoptar uma dieta que já era seguida por milhões de pessoas noutras regiões do mundo. No seu tempo, os primeiros reformadores haviam apregoado um retorno ao Éden vegetariano. O epidemiologista incentivava agora os Americanos a regressarem à dieta dos primórdios da civilização, menos rica em carne e em gordura animal. De um modo geral, Keys recomendava que adoptassem um estilo de vida mais activo ${ }^{66}$ à semelhança daquele das sociedades rurais tradicionais, onde a produção agrícola dependia ainda quase exclusivamente da força braçal. O estudo "Seven Countries" estava então em vias de provar cientificamente que os habitantes das regiões mais pobres do Mediterrâneo eram naturalmente imunes às doenças coronárias. A investigação em curso é explicitamente mencionada logo no início do livro ${ }^{67}$. Durante as primeiras cem páginas, o epidemiologista usa uma linguagem simples e acessível para explicar aos leitores a relação entre o teor de colesterol no seu sangue e o risco de sofrerem um acidente coronário, ensinando-lhes ainda outras noções básicas de nutrição. A segunda parte do livro é dedicada à descrição

\footnotetext{
${ }^{65}$ Keys 1953a: 134.

${ }^{66}$ Keys 1959: 37.

${ }^{67}$ Keys 1959: 7.
} 
dos diferentes tipos de alimentos e à maneira como eles são geralmente preparados nos Estados Unidos, mas também noutras partes do mundo. É de salientar que nenhuma menção é feita neste livro à dieta mediterrânica enquanto tal, mas muitas receitas são retiradas do repertório da cozinha italiana, francesa e espanhola. As recomendações nutricionais propostas aos seus leitores também têm um lugar nesta secção do livro, sendo frequentemente expressas em termos qualitativos, o que é a grande novidade desta obra. Neste espírito, em vez de desenvolver uma lista detalhada de porções de alimentos a ingerir na linguagem quantitativa dos guias do USDA, Keys dá ao seus leitores simples conselhos ${ }^{68}$ :

\section{Do not get fat, if you are fat, reduce.}

2. Restrict saturated fats, the fats in beef, pork, lamb, sausages, margarine, solid shortenings, fats in dairy products.

3. Prefer vegetable oils to solid fats, but keep total fats under $30 \%$ of your diet calories.

4. Favor fresh vegetables, fruits, and non-fat milk products.

5. Avoid heavy use of salt and refined sugar.

6. Good diets do not depend on drugs and fancy preparations.

7. Get plenty of exercise and outdoor recreation.

8. Be sensible about cigarettes, alcohol, excitement, business strain.

9. See your doctor regularly, and do not worry.

Keys partilha também com os seus leitores a sua convicção pessoal de que a dieta dos Americanos deteriorou-se ao longo dos últimos anos, como resultado do desenvolvimento tecnológico e da pressão económica que the está associada. Menciona também o facto de que muitos produtos químicos, entre os quais as gorduras hidrogenadas, serem adicionados aos alimentos comuns, tais como o pão ${ }^{69}$ que os Americanos consomem diariamente. Apesar de reconhecer a necessidade de uma utilização responsável de aditivos químicos nos alimentos, Keys admitirá mais tarde que via com bons olhos o atraso dos países do Mediterrâneo a esse nível, preferindo pessoalmente consumir produtos mais naturais ${ }^{70}$. Tal como Graham, este cientista desconfiava das farinhas refinadas ${ }^{71}$ preferindo o pão "autêntico" que ele teve a oportunidade de comer durante as suas viagens pela Itália e pela França. À semelhança desse pregador $^{72}$, Keys era adepto do pão ázimo que se fazia em algumas áreas do Mediterrâneo desde o período bíblico. Keys chamou ainda a atenção dos seus leitores para o facto de as doenças coronárias serem já a causa de quase metade

\footnotetext{
${ }^{68}$ Keys 1959: 40.

${ }^{69}$ Keys 1959: 109.

${ }^{70}$ Keys 2006: 84.

${ }^{71}$ Keys 1959: 109.

${ }^{72}$ Graham 1837.
} 
das mortes registadas nos Estados Unidos ${ }^{73}$. Ainda assim, reconhecia que a mortalidade devido a acidentes cardiovasculares também era alta em outros países do mundo e até mesmo em alguns países subdesenvolvidos. Ressalvava no entanto que as classes populares não eram habitualmente afectadas nestes países, o que distinguia precisamente das outras nações os Estados Unidos, onde a dieta dos mais pobres é essencialmente a mesma dos ricos. Ninguém estava portanto imune a este flagelo na América ao contrário do que Keys pôde observar em países menos desenvolvidos. Observa ainda que essa tendência já está a alastrar na década de 1950 para outros países ocidentais, como a Finlândia e a Noruega, como os epidemiologistas tiveram a oportunidade de constatar alguns anos antes ${ }^{74}$. Keys considera que a variedade e a quantidade de alimentos à disposição dos consumidores dos Estados Unidos atingiu um grau inimaginável algumas décadas antes. $\mathrm{O}$ cientista constata que a carne, antigamente reservada aos dias de festa, estava agora presente todos os dias à mesa de todas as famílias americanas. Os alimentos preferidos das crianças como as batatas fritas, os bifes e os gelados eram também consumidos diariamente pelas restantes faixas etárias ${ }^{75}$, apesar de uma dieta rica em carne e em gordura animal não ser adequada para suprir as necessidades fisiológicas dos adolescentes e dos adultos ${ }^{76}$. A obesidade, que afectava já mais pessoas nos Estados Unidos do que em qualquer outro país do mundo, era, segundo Keys, em grande parte devida à mudança nos hábitos alimentares que tornou os alimentos ricos em calorias acessíveis a toda a população, inclusive à classe operária que trabalhava em fábricas, onde as tarefas mais penosas passaram a ser asseguradas por máquinas ${ }^{77}$. Keys estava convencido de que o exercício físico era essencial para a saúde e que a sua prática ajudava a manter um peso saudável ${ }^{78}$. Nos países subdesenvolvidos onde essa actividade ainda não estava totalmente mecanizada e a dieta era menos rica em gordura animal ${ }^{79}$, os habitantes pobres das zonas rurais eram menos sujeitos a este tipo de problemas de saúde do que os seus compatriotas que viviam em áreas urbanas como o viria a demonstrar o estudo "Seven Countries". Convicto da veracidade destas duas premissas, Keys encorajava os Americanos a adoptarem um estilo de vida mais próximo do das sociedades camponesas tradicionais e, inclusive, uma dieta alimentar tendencialmente vegetariana ${ }^{80}$, tal como o tinham feito os pregadores puritanos do século anterior.

\footnotetext{
${ }^{73}$ Keys 1959: 21.

${ }^{74}$ Keys 1959: 33.

75 Keys 1959: 19.

${ }^{76}$ Keys 1959: 19.

77 Keys 1959: 66.

${ }^{78}$ Keys 1959: 70.

${ }^{79}$ Keys 1959: 70.

${ }^{80}$ Keys 2006: 30.
} 
Mas contrariamente aos reformadores de outrora, Keys cultivou ao longo da sua vida um certo "intellectual distaste for Christianity" dência a "equate religious devotion with simple-mindedness" 82 . É relevante aqui notar que no seu livro de 1975 Eat well and stay well. The Mediterranean way, este epidemiologista menciona Kellogg - o pregador outrora expulso da sua congregação religiosa - como figura de proa da cruzada contra a carne e não Graham como ainda é hoje costume fazê-lo nos Estados Unidos. Reconhece que as teorias de Kellogg e dos seus antecessores já não tinham qualquer tipo de fundamento científico no estado actual do conhecimento sobre a nutrição humana. Keys faz no entanto questão de frisar logo a seguir que o "Doutor" apenas tinha pecado por excesso. Na sua opinião, muitos cientistas ${ }^{83}$ caíram depois disso numa espécie de culto da proteína animal ${ }^{84}$. Keys acreditava não haver nenhuma razão, de um ponto de vista nutricional, que impedisse os Americanos de reduzirem substancialmente o consumo de carne ${ }^{85}$.

Mas ao contrário dos pregadores puritanos que o precederam, o epidemiologista não queria privar totalmente os seus leitores de determinados tipos de alimentos condenados anteriormente por serem pecaminosos. Keys admite mesmo que as bebidas alcoólicas ${ }^{86}$ fazem parte da vida civilizada ${ }^{87}$, e que todos nós devemos tentar alcançar um equilíbrio entre a satisfação de prazeres no presente e no futuro ${ }^{88}$. Outra novidade desta obra é que, enquanto os guias nutricionais do USDA limitavam-se a quantificar a porção de alimentos que os consumidores deveriam ingerir, o livro de Ancel e Margareth Keys também ensinava a cozinhá-los de forma apetecível. Cem mil exemplares vendidos e a tradução do livro em cinco línguas não deixam dúvidas quanto à eficácia dessa nova estratégia de comunicação.

\section{... CONVERTIDA EM DIETA MEDITERRÂNICA...}

Eat well and stay well é publicado numa altura em que os Americanos estão cada vez mais atraídos por comidas exóticas ${ }^{89}$, levando os Keys a dedicar uma boa parte do livro à apresentação de receitas de especialidades estrangeiras, que eles consideravam serem benéficas para a saúde. Os leito-

\footnotetext{
${ }^{81}$ Tucker 2007: 121 .

${ }^{82}$ Tucker 2007: 129 .

${ }^{83}$ Queria ele antes dizer os seus colegas que influenciavam as políticas nutricionais do

${ }^{84}$ Keys 2006: 74.

${ }^{85}$ Keys 2006: 74.

${ }^{86}$ Convém aqui lembrar que o consumo de álcool ainda era ilegal nos Estados Unidos algumas décadas antes da publicação desse livro.

${ }^{87}$ Keys 1959: 152.

${ }^{88}$ Keys 1959: 14.

${ }^{89}$ Keys 1959: 19.
} USDA? 
res também eram incentivados a experimentar a gastronomia local quando viajassem para o estrangeiro ${ }^{90}$. É através da leitura deste livro que muitos Americanos, sem os recursos necessários para sair do país, ouviram falar pela primeira vez de pratos típicos do sul da Europa, como o gaspacho, a paelha ou os gnocchi, mas também de especialidades oriundas de outras partes do mundo, como a China ou a América Central, que o casal e o seu círculo de amigos tiveram a oportunidade de experimentar pessoalmente ${ }^{91}$. Será apenas em 1975, após a publicação de Eat well and stay well. The Mediterranean way, que as recomendações nutricionais que Keys tinha compilado pela primeira vez no seu livro de 1959, são agora associadas claramente ao que ele baptiza de "dieta mediterrânica"

O epidemiologista começa por explicar aos seus leitores que se trata de um livro sobre o que comem as classes populares na Grécia, na Itália e na costa mediterrânea da França e da Espanha ${ }^{93}$. Convida os seus leitores a introduzir alguns dos pratos que fazem parte do dia a dia dos habitantes desta região do mundo nas suas ementas quotidianas. No prólogo, Keys ${ }^{94}$ explica que poderia muito bem ter escolhido outras cozinhas tradicionais como a da Coreia, do Japão ou de Taiwan. Admite que qualquer um desses casos de estudo poderia facilmente servir para provar a existência de uma relação muito estreita entre a dieta, o teor de colesterol no sangue e a probabilidade de sofrer de problemas cardiovasculares. Afirma ainda que a sua escolha acabou por recair sobre esses países do sul da Europa para evitar, em primeiro lugar, que os seus críticos invocassem as diferenças fisiológicas entre Caucasianos e Asiáticos para refutar a natureza universal desta relação. Em segundo lugar, porque ele acreditava que seria muito difícil convencer os Americanos a abandonarem a sua dieta habitual para adoptar as preparações culinárias que lhes eram totalmente estranhas. É talvez por essa razão que a costa mediterrânea da França ${ }^{95}$, que já era desde longa data o país de eleição dos Norte-americanos que viajavam para a Europa, toma agora o lugar da Jugoslávia, inacessível aos turistas por este país estar situado do outro lado da Cortina de Ferro. A escolha da Espanha era, além disso, sustentada por um estudo levado a cabo por Keys na mesma época daquele de Nápoles, que permitiu ao cientista verificar, uma vez mais, que a mortalidade causada por eventos cardiovasculares era muito menor nesse país do que nos Estados Unidos ${ }^{96}$.

\footnotetext{
${ }^{90}$ Keys 1959: 130.

${ }^{91}$ Keys 1959: 6.

${ }^{92}$ Levenstein 2012: 137.

${ }^{93}$ Keys 2006: 27.

${ }^{94}$ Keys 2006: 21.

${ }^{95}$ Keys 2006: 27.

${ }^{96}$ Keys 1953b: 1402.
} 
Os Americanos começavam então a descobrir os sabores do Sul da Europa. Muitos soldados que combateram os nazis durante a campanha italiana tiveram um contacto directo com a cozinha local ${ }^{97}$. Os turistas americanos elegiam também cada vez mais a Itália e a Espanha como destino de férias, tendo assim a oportunidade de desfrutar "a" versão autêntica das especialidades destes países ${ }^{98}$. Por outro lado, a pizza importada para Nova York pelos imigrantes napolitanos no século XIX, tornou-se a comida preferida dos jovens americanos na década de 1960, quando surgem as primeiras cadeias de fast food, que se dedicam exclusivamente à sua comercialização ${ }^{99}$. Todos estes factores, faziam com que, apesar de ser exógena, a gastronomia do Sul da Europa fosse facilmente identificada por muitos Americanos, tornando a recém-nascida "dieta mediterrânica" apetecível aos seus olhos.

\section{... CONVERTIDA EM INSTRUMENTO DE GOVERNAMENTALIDADE ${ }^{100}$...}

A American Heart Association (AHA) será, desde o início, o principal aliado de Keys na sua guerra contra o colesterol. O seu director, Paul Dudley White, um médico que ficou famoso por ter tratado o Presidente Eisenhower após um ataque cardíaco em 1955, tinha fundado em 1924 esta instituição, que irá dirigir a partir de 1941. É autor do prefácio de Eat well and stay well, que escreveu em Creta enquanto acompanhava os trabalhos de campo da delegação grega da equipa do estudo "Serven Countries"101. White estava totalmente convencido da existência de uma relação directa entre o risco coronário e um estilo de vida inadequado. Ao longo da sua vida, apoiará abertamente as ideias de Keys e fará uso da sua influência na Casa Branca para promover a causa da luta contra o colesterol junto do Estado federal ${ }^{102}$.

A AHA foi pioneira em encorajar os Americanos a comerem menos gordura. Esta instituição já fazia lobby no início da década de 1970 em prol de políticas estatais incentivando os Americanos a adoptar uma dieta mais moderada. As agências governamentais que, até aí, tinham aconselhado os Americanos a comerem mais de tudo, tiveram no início alguma dificuldade em aceitar que o consumo excessivo de comida se tinha tornado um problema de primeira ordem à escala nacional, apesar de as doenças cardio-vasculares

\footnotetext{
${ }^{97}$ Levenstein 1993: 90.

${ }^{98}$ Levenstein 2004: 206.

${ }^{99}$ Almeida-Topor 2006: 218.

${ }^{100}$ Governamentalidade é aqui usada no sentido que Michel Foucault (2004: 111-112) dava a este termo, ou seja, enquanto conjunto de instituições, de técnicas e de saberes permitindo "conduzir as condutas" individuais em função de objectivos societais como é o caso da reforma dos hábitos alimentares que é aqui abordada numa perspectiva diacrónica.

101 Keys 1959: 8.

${ }^{102}$ Levenstein 2012: 131.
} 
já afectarem mais de 30 milhões de Americanos nessa altura. O relatório "Dietary Goals for the United States", tornado público pelo Select Committee on Nutrition and Human Needs (SCNHN) em 1977, marca o momento da ruptura com as campanhas nutricionais do passado. A palavra de ordem será, a partir de então, reduzir e não consumir mais de tudo. O consumo de carne, ovos, manteiga e pratos doces ou salgados também deveria ser moderado de ora em diante. Os Americanos eram agora aconselhados a comer mais cereais, frutas, legumes e frutas secas e reduzir ao mesmo tempo o consumo de carne se quisessem ter uma vida longa e saudável. Temos hoje tendência a esquecer que foi somente há cerca de quarenta anos atrás que o consumo excessivo de gordura, especialmente de gordura saturada, de alimentos ricos em colesterol, açúcar e sal foi pela primeira vez abertamente considerado nocivo por um organismo de saúde estatal.

O sector agro-alimentar, que tinha dado, até à data, todo o seu apoio ao USDA expressou imediatamente o seu desacordo perante esta mudança de posição do Estado federal que colocava em risco a venda de alimentos até então preferidos pelos consumidores e especialmente a carne. A pressão exercida pelos representantes da indústria no Congresso foi frutífera. Uma versão revista do relatório será apresentada pelo SCNHN no final do mesmo ano, denunciando de forma mais dura os riscos da obesidade e do consumo excessivo de álcool, sendo ao mesmo tempo mais indulgente no que toca ao consumo da carne, dos ovos e do sal ${ }^{103}$. Dois anos mais tarde, os produtores de carne reagiram novamente contra uma recomendação do Department of Health, Education, and Welfare, apelando à redução do consumo de carne vermelha. A pressão do lobby da carne não é também alheia ao facto de os guias nutricionais federais publicados na década de 1980 não prejudicarem de forma tão frontal os interesses dessa indústria ${ }^{104}$.

Outras organizações de saúde não-governamentais juntaram-se desde então à AHA, consciencializando gradualmente a sociedade civil e o Estado norte-americano para a necessidade de políticas contra o consumo excessivo de alimentos susceptíveis de aumentar o risco coronário. O estudo "Seven Countries" teve um papel muito importante neste processo, sendo essa ideia já relativamente consensual no seio da comunidade científica no final dos anos 1970. O crescente interesse do público, ao longo da década seguinte, pelas questões de saúde relacionadas com a nutrição contribuiu para alargar a base social desse consenso, a ponto de influenciar de forma duradoira as políticas governamentais de foro alimentar. A dieta vegetariana, preconizada pelos primeiros reformadores por razões espirituais foi a partir de então

\footnotetext{
${ }^{103}$ Nestle 2007: 41.

${ }^{104}$ Nestle 2007: 46.
} 
mobilizada por uma nova causa social: o ambientalismo. Após o sucesso do livro publicado por F. M. Lappe nos anos 1970 intitulado $A$ diet for a small

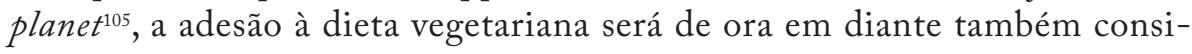
derada por todo um movimento neo-vegetariano não só como a garantia de viver mais tempo e com mais saúde, mas também como um meio de salvar o ecossistema da pressão exercida pela produção de carne em massa, entendida como uma ameaça ao equilíbrio ecológico do planeta. Muitos Americanos estavam agora desconfiados dos grandes grupos económicos que culpavam pelo desastre militar do Vietnam ${ }^{106}$. Tal como o complexo "militaro-industrial", o sector agro-alimentar exercia uma forte pressão sobre o Congresso e sobre o USDA para garantir a defesa dos seus interesses corporativos. O USDA era, e é ainda hoje, uma presa fácil para este lobby, na medida em que a missão da instituição é encorajar os Americanos a adoptarem uma dieta saudável e promover ao mesmo tempo o desenvolvimento dessa indústria ${ }^{107}$.

Os produtores de carne, contudo, continuaram a opor-se veementemente a qualquer menção explícita à redução do consumo de carne nas campanhas de informação federais ao longo da década seguinte. Em 1991, a publicação da primeira pirâmide nutricional inspirada nas ideias de "Negative Nutrition" foi, assim, adiada pelo USDA porque o lobby da carne via com maus olhos que esse tipo de alimento ocupasse o patamar superior nesta nova forma de representação do modelo alimentar preconizado por essa agência governamental. Os meios de comunicação social deram rapidamente uma grande cobertura mediática à polémica em volta da pirâmide ${ }^{108}$. Desta vez, a opinião pública já não iria tolerar que o Congresso dos EUA cedesse à pressão dos produtores de carne. Uma versão ligeiramente modificada da pirâmide do USDA acabará por ser dada a conhecer oficialmente no ano seguinte num guia alimentar, publicado pela primeira vez em 1992 por esta instituiçãa ${ }^{109}$ e, posteriormente, só ligeiramente revista em 2005. Os hidrocarbonatos ocupavam a base da pirâmide imediatamente abaixo dos legumes e das frutas (Figura 1). As gorduras e os alimentos açucarados ocupavam finalmente o topo da pirâmide, logo acima de lacticínios, das carnes e dos peixes.

A pirâmide do USDA servirá mais tarde de inspiração para a pirâmide da dieta mediterrânica, que a comunicação social dará a conhecer ao público em geral, um ano depois ${ }^{110}$ e que agora tende a ser confundida com esta primeira pirâmide. Desde então, as similitudes entre ambas as representações têm vindo

\footnotetext{
${ }^{105}$ Lappe 1991.

${ }^{106}$ Levenstein 1997: 855.

${ }^{107}$ Nestle 2007: 53 .

${ }^{108}$ Nestle 2007: 58 .

${ }^{109}$ Willett et alii 1995: 1402S.

${ }^{110}$ Willett et alii 1995.
} 
a reforçar erroneamente o sentimento de continuidade entre a ideia de dieta mediterrânica saudável e as recomendações dietéticas divulgadas pelos guias do USDA no passado, obliterando quase por completo a cruzada contra a carne iniciada pelos pregadores puritanos um século antes, retomada algumas décadas mais tarde pelos epidemiologistas. Após se tornar um instrumento de governamentalidade, a dieta mediterrânica teve uma existência social totalmente autónoma do contexto cultural da sua "descoberta", sendo posta em prática noutras regiões do mundo. A inscrição da dieta mediterrânica na Lista do Património Cultural Imaterial da Humanidade marca uma nova etapa da história deste ideal alimentar convertido em tradição milenar agora ao serviço das comunidades mediterrânicas, enquanto instrumento de promoção de uma identidade cultural partilhada.

\section{Agradecimentos}

Quero agradecer a Maria de Fátima Marques da Silva e Liliana Gonçalves Pereira pela releitura atenta deste texto. Qualquer erro é, no entanto, da minha inteira responsabilidade.

\section{Bibliografia}

Allbaught, L. (1953), Crete: a case study of an underdeveloped area, Princeton University Press, Princeton.

Almeida-Topor, H. (2006), Le goût de l'étranger. Les saveurs venues d'ailleurs depuis la fin du XVIII' siècle, Armand Colin, Paris.

Atwater,W.O.(1895), US Department of Agriculture, Food and diet, Yearbook of Agriculture, Government Printing Office, Washington, 357-388.

Atwater, W. O. (1902), "Principles of nutrition and nutritive value of food", Farmer's Bulletin 142: 5-48.

Bevilacqua, S. (2010), "Un « régime méditerranéen » bon à penser", Anthropology of food 7 / dezembro, http://aof.revues.org/6600.

Blackburn, H. (1999), On the trail of heart attacks in seven countries, School of Public Health - University of Minnesota, http://www.sph.umn.edu/.

Dernini, S., Berry, E. M., Bach-Faig, A., Belahsen, R., Donini, L. M., Lairon, D., Serra-Majem, L. e Cannella, C. (2012), "Un modèle alimentaire construit par les scientifiques", in CIHEAM (dir.), Mediterra 2012 - La diète méditerranéenne pour un développement régional durable, Presses de Sciences-Po, Paris, 73-91.

Farley, J. (2004), To cast out disease. A history of the international health division of the Rockefeller Foundation (1913-1951), Oxford University Press, Oxford.

Ferrières, M. (2002), Histoire des peurs alimentaires du moyen âge à l'aube du XXe siècle, Seuil, Paris.

Foucault, M. (2004, [1978]), Sécurité, territoire, population. Cours au Collège de France (1977/1978), Gallimard/Seuil, Paris. 
Graham, S. (1837), Treatise on bread and bread-making, Light \& Stearns, Boston.

Graham, S. (1849), Lecture on the Science of Human life, Horsell \& Aldine Chambers, Londres.

Haber, B. (1997), “The Mediterranean diet : a view from history”, American Journal of Clinical Nutrition 66 (suppl.): 1053S-1057S.

Keys, A. (1953a), "Atherosclerosis : a problem in newer public health ", Journal of the Mont Sinai Hospital 20(2): 118-139.

Keys, A. (1953b), "Prediction and possible coronary disease", American Journal of Public Healt 43: 1399-1407.

Keys, A. (1980), Seven Countries. A multivariate analysis of death and coronary heart disease, Harvard University Press, Cambridge e Londres.

Keys, A. (1995), "Mediterranean Diet and Public Health: Personal Reflections", American Journal of Clinical Nutrition 61 (suppl.): 1321S-23S.

Keys, A. e Keys, M. (1959), Eat well and stay well, Doubleday, New York.

Keys, A. e Keys, M. (2006, [1975]), Comer bien, sentirse bien. La receta mediterránica, Fundación Dieta Mediterránea, Barcelona.

Keys, A., Fidanza, F., Scardi, U., Bergami, G., Keys, M. H. e Lorenzo, F. di. (1954), "Studies on serum cholesterol and other characteristics on clinically healthy men in Naples", Archives of Internal Medecine 93: 328-336.

Koliopoulos, J. S. e Veremis, T. M. (2002), Greece - the modern sequel. From 1831 to the present, C Hurst \& C. Ltd, Londres.

Laiou-Thomadakis, A. (1980), "The politics of hunger: economic aid to Greece, 19431945", Journal of the Hellenistic Diaspora 7(2): 43-50.

Lappe, F. M. (1991, [1971]), Diet for a small planet, Ballantines Books, New York.

Lavabre-Bertrand, T. (2013), "La conception ternaire corps/esprit/âme dans la pensée médicale au cours des âges", Cabiers d'études du religieux. Recherches interdisciplinaires [En ligne] 12, URL : http://cerri.revues.org/1245.

Levenstein, H. A. (1993), Paradox of plenty. A social history of eating in modern America, Oxford University Press, New York.

Levenstein, H. A. (1997), "Diététique contre gastronomie : traditions culinaires, sainteté et santé dans les modèles de vie américains”, in J.-L Flandrin e M. Montanari, (coords.), Histoire de l'alimentation, M. Fayard, Paris, 843-858.

Levenstein, H. A. (2003, [1988]), Revolution at the table. The transformation of the American diet, University of California Press, Berkeley e Los Angeles.

Levenstein, H. A. (2004), We'll always have Paris. American tourists in France since 1930, The University of Chicago Press, Chicago and London.

Levenstein, H. A. (2012), Fear of food: a history of why we worry about what we eat, University of Chicago Press, Chicago.

Meyer-Renschhausen, E. e Wirz, A. (1999), “Dietetics, health reform and social order : vegeterianism as a moral physiology. The example of Maximilian Bircher-Benner (1867-1939)", Medical History 43: 323-341. 
Nestle, M. (1995), "Mediterranean diets : historical and research overview”, American Journal of Clinical Nutrition 61 (suppl.): 1313S-1320S.

Nestle, M. (2007, [2002]), Food politics. How the food industry influences nutrition and health, University of California Press, Berkeley-Los Angeles-Londres.

Palma, G. et Padilla, M. (2012), "La « méditerranéisation » des modes alimentaires dans le monde”, in CIHEAM (dir.), Mediterra 2012 - La diète méditerranéenne pour un développement régional durable, Presses de Sciences-Po, Paris, 141-159.

Poulain, J.-P. (2002), Sociologies de l'alimentation, Presses Universitaires de France, Paris.

Poulain, J.-P. (2006), “Les modèles alimentaires méditerranéens : un héritage pluriel à étudier pour en faire un label pour le futur", Horizons Maghrébins 55: 8-28.

Reguant-Aleix, J. (2012), "La diète méditerranéenne : donner un nom au futur”, in CIHEAM (dir.), Mediterra 2012 - La diète méditerranéenne pour un développement régional durable, Presses de Sciences-Po, Paris, 29-51.

Rockefeller (1948), The Rockefeller foundation annual report, Rockefeller Foundation, New York.

Rosenberg, C. E. (1997, [1976]), No other God, on science and American social thought, John Hopkins University Press, Baltimore.

Silva, A. J. M. (2013), Un ingrédient du discours. Discours et pratiques alimentaires en Méditerranée (vol. I), Édilivre, Saint Denis.

Silva, A. J. M. (2015), La diète méditerranéenne. Discours et pratiques alimentaires en Méditerranée (vol. II), L'Harmattan, Paris.

Stiebeling, H. K. e Ward, M. M. (1933), Diets at four levels of nutritive content and cost, USDA, Washington.

Tucker, T. (2007), The great starvation experiment. Ancel Keys and the men who starved for Science, University of Minnesota Press, Minneapolis.

Turmo, I. G. e Medina, F.-X. (2012), "Défis et responsabilités suite à la déclaration de la diète méditerranéenne comme patrimoine culturel immatériel de l'humanité (Unesco)”, Revue d'Ethnoécologie [En ligne], http://ethnoecologie.revues.org/957.

Voglis, P. (2006), "Surviving hunger: life in the cities and the countryside during the occupation”, in R. Gildea, O. Wieviorka, e A. Warring, (eds.), Surviving Hitler and Mussolini: daily life in occupied Europe, Berg, New York, 16-41.

Willett, W. C., Sacks, F., Trichopoulou, A., Drescher, G., Ferro-Luzzi, A., Helsing, E. e Trichopoulos, D. (1995), "Mediterranean diet pyramid: a cultural model for healthy eating", American Journal Clinical Nutrition 61/suppl. 6: 1402S-1406S. 